\title{
Bazalt ve Karbon Lif Takviyeli Betonlarm Fiziksel ve Mekanik Özelliklerinin Araştırılması
}

\author{
Investigation of Physical and Mechanical Properties of Basalt and Carbon Fiber \\ Reinforced Concrete
}

\author{
Behçet DÜNDAR*1,a, Emriye ÇINAR ${ }^{1, b}$, Servet PEŞİ ${ }^{1, c}$ \\ ${ }^{1}$ Osmaniye Korkut Ata Üniversitesi, İnșaat Mühendisliği Bölümü, Mühendislik Fakültesi, 80010, Osmaniye
}

• Geliş tarihi / Received: 09.03.2020 • Düzeltilerek geliş tarihi / Received in revised form: 15.06.2020 • Kabul tarihi / Accepted: 10.09.2020

\begin{abstract}
Öz
Bu çalışmada farklı lif çeşitleri kullanılarak üretilen betonların fiziksel ve mekanik özellikleri incelenmiştir. Betonların üretiminde su/çimento oran 0.55 ve çimento miktarı da $300 \mathrm{~kg} / \mathrm{m}^{3}$ olarak sabit tutulmuştur. Agrega olarak $0-4 \mathrm{~mm}$ tane büyüklüğüne sahip kırma kum ve 4-16 mm boyutlarına sahip kırma taş agregası kullanılmıştır. Lif çeşiti olarak bazalt ve karbon seçilip beton içerisine hacimce $\% 0.5, \% 1, \% 1.5$ ve $\% 2$ oranlarında ilave edilmiştir. Basınç dayanımı ve arşimet tartımları için 100x100x100 mm, eğilme dayanım tayini için 100x100x350 mm, böhme (aşınma) deneyi için 71x71x71 mm boyutlarında beton numuneleri üretilmiştir. Beton numuneleri arşimet, ultrases, böhme (aşınma), eğilme ve basınç deneylerine tabi tutulmuştur. Beton numuneler kalıptan alındıktan sonra 7 ve 28 gün süre ile standart kür havuzunda kür edilmiştir. 7. günü dolduran beton numunelerinin basınç dayanımları ölçülmüştür. 28 günü dolduran numunelerin su emme yüzdesi, porozite ve birim hacim ağıllık, böhme deneyindeki ağırlık kayıpları gibi fiziksel özellikleri belirlenip, eğilme ve basınç dayanımları ölçülmüştür. Lif oranının artmasıyla birlikte su emme ve porozite değerlerinde artış gözlemlenmiştir. Ultrases geçiş hızları incelendiğinde bazalt lifi kullanılan numunelerde karbon lifi kullanılan betonlara oranla daha yüksek olduğu gözlemlenmiştir. Mekanik dayanımlarda ve aşınma dirençlerinde bazalt lifinin karbondan daha fazla direnç gösterdiği gözlemlenmiştir.
\end{abstract}

Anahtar kelimeler: Bazalt Lif, Karbon Lif, Lifli Takviyeli Beton

\begin{abstract}
In this study, physical and mechanical properties of concretes produced by using different fiber types were investigated. In the production of concrete, the water / cement ratio was kept as 0.55 and the cement amount was kept constant as $300 \mathrm{~kg} / \mathrm{m}^{3}$. As aggregate, $0-4 \mathrm{~mm}$ crushed sand and $4-16 \mathrm{~mm}$ crushed stone aggregate were used. Basalt and carbon were selected as fiber type and $0.5 \%, 1 \%, 1.5 \%$ and $2 \%$ by volume were added to the concrete. Concrete samples with dimensions of 100x100x100mm for compressive strength and Archimedes weighing, 100x100x350mm for determination of flexural strength and $71 \times 71 \times 71 \mathrm{~mm}$ for abrasion test were produced. Concrete samples were subjected to Archimedes, ultrasounds, abrasion, bending and pressure tests. The concrete samples were cured in the standard curing pool for 7 and 28 days after being taken from the mold. The compressive strength of the concretes filled on the 7th day were measured. The physical properties of the samples that were completed after 28 days such as water absorption percentage, porosity and unit volume weight, weight losses in bending test were determined and their flexural and compressive strengths were measured. Water absorption and porosity values increased with increasing fiber ratio. When the ultrasound transition rates were examined, it was observed that the samples using basalt fiber were higher than the concretes using carbon fiber. It has been observed that basalt fiber has more resistance than carbon in mechanical strength and abrasion resistance.
\end{abstract}

Keywords: Basalt Fiber, Carbon Fiber, Fiber Reinforced Concrete

\footnotetext{
*a Behçet DÜNDAR; behcetdundar@osmaniye.edu.tr, Tel: (0554) 58343 06, orcid.org/0000-0003-0724-9496

${ }^{\mathrm{b}}$ orcid.org/0000-0002-9435-2935 ${ }^{\mathrm{c}}$ orcid.org/0000-0000-0000-0000
} 


\section{Giriş}

Çimento esaslı malzemeler çekme dayanımı açısından zayıf malzemeler olduğundan betonun kırılgan bir davranışı sonucu çatlakların oluşması kaçınılmazdır (Hameed vd., 2010; Kaufmann 2013). Uygulanan yük betonun çekme dayanımını aştığında, farklı büyüklüklerde çatlaklar oluşur (Shah, 1992; Park vd.,2017). Ek olarak, betonun büzülmesi, erken aşamalarda çatlamaya ve daha sonra zararlı maddelere maruz kalma sonucu beton yapısının hizmet verilebilirliğinin kısalmasina neden olabilir (Afroughsabet vd., 2019). Beton karışımına lif eklenmesi, çatlak oluşumunu geciktirerek çatlak yayılımını engellediğinden betona süneklik kazandırırlar (Thomas, 2007; Alberti vd., 2017). Yüksek mukavemet, tokluk ve dayanıklılık için liflerle güçlendirilmiş yüksek performanslı betonlar geliştirilmiştir (Habel vd., 2006; Afroughsabet vd., 2016). Ayrık liflerin ilavesi, artan mekanik özelliklere sahip kompozitlerin imalatında uygun bir çözüm olarak kabul edilir ve bu sayede çatlakların yayılmasını kontrol eder (Biolzi vd., 2000; Biolzi vd., 2017). Ayn1 zamanda lifler, beton matrisinin sünekliğini arttırdığından eğilme deformasyonunu azaltabilir, fiziksel olarak büzülmeyi sınırlandırmaya katkıda bulunur veya çatlakları kontrol eder (Li vd., 2006). Bununla birlikte, lif takviyeli betonlarda lifin kazandırdığ süneklik, tokluk gibi kazandırdığı özellikler, lif tipi, lif elastik modülü ve lifin en boy oranı gibi önemli faktörlere bağlı olarak değişmektedir (Barr vd., 2003) Son yıllarda yapılan araştırmalar, ayrık lif kullanımının mekanik yükler altında ani parçalanmalara karşı dayanımı ve sünekliği büyük ölçüde arttırdığını ve geleneksel betonarme elemanın nihai dayanım yükünü aşan yapısal bütünlüğü koruduğunu göstermiştir (Sicakumar ve Santhanam, 2004). Yeni tasarım ve teknoloji sayesinde, lif betonun kırılma tokluğunu, yorulma direncini, darbe dayanımını, eğilme dayanımı, 1sıl çatlak direncini vb. iyileştirebileceğini ortaya koymaktadır. $\mathrm{Bu}$ iyileştirmenin büyüklügü, kullanılan liflerin miktarına ve türüne bağlıdır (Craig 1987; Campione vd., 2006). Lifler çatlakları köprüleyerek betonun sünekliğini arttırır. Liflerin köprülenme hareketi, çekme direnciyle ilgilidir ve elemanlarda dağınık çatlaklara neden olur. Ayrıca, kompozitin yüksek çekme dayanımı ve çekme kapasitesi nedeniyle, boyuna çelik donatılarda yüksek çekme deformasyonları söz konusudur ve sonuç olarak elemanların yüksek sünekliğine ulaşılmaktadır. Beton içerisinde kullanılan polipropilen, cam, aramid, bazalt ve karbon lif çeşidi bulunmaktadır. Bazalt lif, çevre dostu ve yüksek performanslı özelliklere sahip ve birçok alanda yaygın olarak kullanılmaktadır (Kızılkanat vd., 2015; Jiang vd., 2014; Branston vd., 2016). Bazalt lifi, çimento bağlayıcılı kompozitlerin kırılma enerjisinin yanı sıra eğilme dayanımı ve tokluğu artırabilir (Ralegaonkar vd., 2018). Karbon lifi, günümüzde yüksek dayanımlı, yüksek elastisite modüllü, hafifliği ve yüksek aşındırıcılık direncinin gibi özelliklerinden kaynaklı çimento esaslı malzemelerdeki kullanımı konusunda yoğun ilgi görmektedir (Chung, 2000; Gao vd., 2018). Bu çalışmada hem lif kullanımının hem de lif çeşidi farklılığının betonun fiziksel ve mekanik özellikleri üzerine etkisinin incelenmesi amaçlanmıştır. $\mathrm{Bu}$ amaç doğrultusunda lif çeşidi olarak bazalt ve karbon seçilmiştir. Betonların üretiminde net su/çimento oranı 0,55 ve çimento miktarı da $300 \mathrm{~kg} / \mathrm{m} 3$ olarak sabit tutulmuştur. Lif tipi olarak bazalt ve karbon seçilip beton içerisine hacimce $\% 0,5, \% 1, \% 1,5$ ve $\% 2$ oranlarinda ilave edilmiştir. Lif takviyesi Beton numuneleri arşimet, ultrases, böhme(aşınma), eğilme ve basınç deneylerine tabi tutulmuştur. Lif oranının artmasiyla birlikte su emme ve porozite değerlerinde artış gözlemlenmiştir. Ultrases geçiş hızları incelendiğinde bazalt lifi kullanılan numunelerde karbon lifi kullanilan betonlara oranla daha yüksek olduğu gözlemlenmiştir. Mekanik dayanımlarda ve aşınma dirençlerinde bazalt lifinin karbondan daha fazla direnç gösterdiği gözlemlenmiştir.

\section{Materyal ve Metot}

\subsection{Materyal}

Betonların üretiminde su/çimento oranı 0,55 ve çimento mikterı da $300 \mathrm{~kg} / \mathrm{m} 3$ olarak sabit tutulmuştur. Birim hacim için (1 m3) için gerekli olan malzeme miktarları Tablo 1'de verilmiştir. Beton üretiminde üretimin de bağlayıcı olarak TS EN 197-1 (2012)'e uygun CEM I $42.5 \quad R$ çimentosu kullanılmıştır ve özellikleri Tablo 2'de verilmiştir. Beton üretiminde $0-4 \mathrm{~mm}$ kırma kum ve $4-16$ mm kırma taş kullanılmıştır. Deneylerde kullanılan kırma kumun deneylerde kullanım uygunluğu TS 706 EN $12620+\mathrm{A} 1 \quad$ (2009) standartlarından kontrol edilmiştir. Betonda en büyük tane boyutu $16 \mathrm{~mm}$ olarak belirlenmiştir. İnce ve iri agreganın yüzey kuru suya doygun yoğunlukları sirasiyla 2.67 ve $2.70 \mathrm{~g} / \mathrm{cm}^{3}$ 'dir. Kullanılan agregaların granülometrisi standartlara uygundur. Numune kodlamas1 yapilırken lif içermeyen beton numuneleri Ref. kısaltması ile ifade edilirken, lif takviyeli betonlarda kullanılan lifin ilk harfi ve yüzde oranı yazılacak şeklinde kodlanmıştır (örneğin; B0.5: Bazalt lifinin \%0.5 
oranında kullanıldığı anlamına gelmektedir). Bazalt ve karbon olmak üzere iki çeşit lif kullanılmıştır. Kullanılan liflerin özellikleri üretici firmalar tarafından temin edilmiştir. Temin edilen liflerin teknik özellikler Tablo 3 ve Tablo 4'te verilmiştir.

Tablo $1.1 \mathrm{~m}^{3}$ beton için gerekli malzeme miktarları

\begin{tabular}{cccccccc}
\hline $\begin{array}{c}\text { Numune } \\
\text { Adı }\end{array}$ & $\begin{array}{c}\text { Çimento } \\
\left(\mathbf{k g} / \mathbf{m}^{\mathbf{3}}\right)\end{array}$ & $\begin{array}{c}\text { Su } \\
\left(\mathbf{k g} / \mathbf{m}^{\mathbf{3}}\right)\end{array}$ & $\begin{array}{c}\text { Kum } \\
\left(\mathbf{k g} / \mathbf{m}^{\mathbf{3}}\right)\end{array}$ & $\begin{array}{c}\text { Agrega } \\
\left(\mathbf{k g} / \mathbf{m}^{\mathbf{3}}\right)\end{array}$ & $\begin{array}{c}\text { Kim. } \\
\mathbf{K .} .\left(\mathbf{k g} / \mathbf{m}^{\mathbf{3}}\right)\end{array}$ & $\begin{array}{c}\text { Karbon Lif } \\
\left(\mathbf{k g} / \mathbf{m}^{\mathbf{3}}\right)\end{array}$ & $\begin{array}{c}\text { Bazalt Lif } \\
\left(\mathbf{k g} / \mathbf{m}^{\mathbf{3}}\right)\end{array}$ \\
\hline Ref. & 350 & 175 & 1030 & 845 & 3.5 & 0 & 0 \\
B0.5 & 350 & 175 & 1030 & 845 & 3.5 & 0 & 4.54 \\
B1.0 & 350 & 175 & 1030 & 845 & 3.5 & 0 & 9.08 \\
B1.5 & 350 & 175 & 1030 & 845 & 3.5 & 0 & 13.62 \\
B2.0 & 350 & 175 & 1030 & 845 & 3.5 & 0 & 18.16 \\
K0.5 & 350 & 175 & 1030 & 845 & 3.5 & 4.54 & 0 \\
K1.0 & 350 & 175 & 1030 & 845 & 3.5 & 9.08 & 0 \\
K1.5 & 350 & 175 & 1030 & 845 & 3.5 & 13.62 & 0 \\
K2.0 & 350 & 175 & 1030 & 845 & 3.5 & 18.16 & 0 \\
\hline
\end{tabular}

Tablo 2. CEM I $42.5 \mathrm{R}$ tipi çimentonun fiziksel ve kimyasal özellikleri

\begin{tabular}{cc}
\hline Kimyasal Analiz (\%) & CEM I 42.5R \\
\hline $\mathrm{CaO}$ & 64.7 \\
$\mathrm{SiO}_{2}$ & 20.7 \\
$\mathrm{Al}_{2} \mathrm{O}_{3}$ & 5.55 \\
$\mathrm{Fe}_{2} \mathrm{O}_{3}(\%)$ & 2.9 \\
$\mathrm{MgO}(\%)$ & 2.58 \\
$\mathrm{SO}_{3}(\%)$ & 2.76 \\
Diğer Özellikleri & \\
\hline Kızdırma Kaybı (\%) & 3.26 \\
Yüzey alanı (cm $\left.{ }^{3} / \mathrm{g}\right)$ & 3102 \\
Hacim Genleşmesi (mm) & 1 \\
Priz Başı (dk) & 260 \\
Priz Sonu (dk) & 300 \\
\hline
\end{tabular}

Tablo 3. Bazalt lifin teknik özellikleri (URL1)

\begin{tabular}{cc}
\hline Teknik Özellikler & Bazalt Lif \\
\hline Çekme Dayanımı & $4840 \mathrm{Mpa}$ \\
Elastisite Modülü & $89 \mathrm{Gpa}$ \\
Uygulama Sıcaklık limitleri & $-260^{\circ} \mathrm{C}-+982^{\circ} \mathrm{C}$ \\
Erime Sicaklı̆̆ & $1450^{\circ} \mathrm{C}$ \\
Özgül Ağırlık & $2.60-2.80 \mathrm{~g} / \mathrm{cc}$ \\
Lif Çapı & $9-23 \mathrm{mikron}$ \\
Lif Uzunluğu & $12 \mathrm{~mm}$ \\
\hline
\end{tabular}

\subsection{Metot}

\subsubsection{Eğilme-Basınç Deneyi}

Beton numunelerinin eğilme-basınç tayini deneyleri için, 100x100x100 mm ve 100x100x350 $\mathrm{mm}$ boyutlarında numuneler üretilmiştir. 24 saat kalıpta prizini tamamlayan beton numuneleri kalıplardan çıkartılarak 7 gün süre ile kür edildikten sonra basınç dayanımı tayin edilmiştir. Kür havuzunda 28 gün süre ile kür edilen numunelerin hem basınç hem de eğilme dayanımları tayin edilmiştir. Eğilme ve basınç dayanımları 200 ton kapasiteli TS EN 12390-4 (2019) standardına uygun cihaz aracılı̆g ile uygulanmıştır. Basınç dayanımı TS EN 12390-3 (2019) standardına göre eğilme dayanımı ise TS EN 12390-5 (2019) standardına göre belirlenmiştir.

Tablo 4. Karbon lifin teknik özellikleri (URL1)

\begin{tabular}{cc}
\hline Teknik Özellikler & Karbon Lif \\
\hline Isıl iletkenlik & $20 \mathrm{~W} / \mathrm{M}^{\times K}$ \\
Germe Modülü & $220-240 \mathrm{GPa}$ \\
Germe Dayanımı & $3450-4850 \mathrm{Mpa}$ \\
Kopma uzaması & $\% 1.6-2.2$ \\
Özgül Ağırlık & $1.8 \mathrm{~g} / \mathrm{cm}^{3}$ \\
Lif Çapı & $5-8 \mu \mathrm{m}$ \\
Lif Uzunluğu & $12 \mathrm{~mm}$ \\
\hline
\end{tabular}

\subsubsection{Böhme Deneyi}

Sürtünme ile aşınma kaybı deneyi için TS 2824 EN 1338 (2005)'e uygun olarak kenar uzunlukları $71 \mathrm{~mm}$ olan küp biçiminde deney numuneleri hazırlanmıştır. $\mathrm{Bu}$ numunelerde temas eden ve ona karşı gelen yüzü paralel ve düz olmalıdır. Deneylerde $20 \mathrm{~g}$ zımpara tozu sürtünme şeridi üzerine serpilir ve çelik manivela aracılığı ile 294 $\mathrm{N}$ ile yüklenir. 22 devir sonunda otomatik olarak duran disk üzerinden zımpara tozu ve numune atıkları temizlenir. 


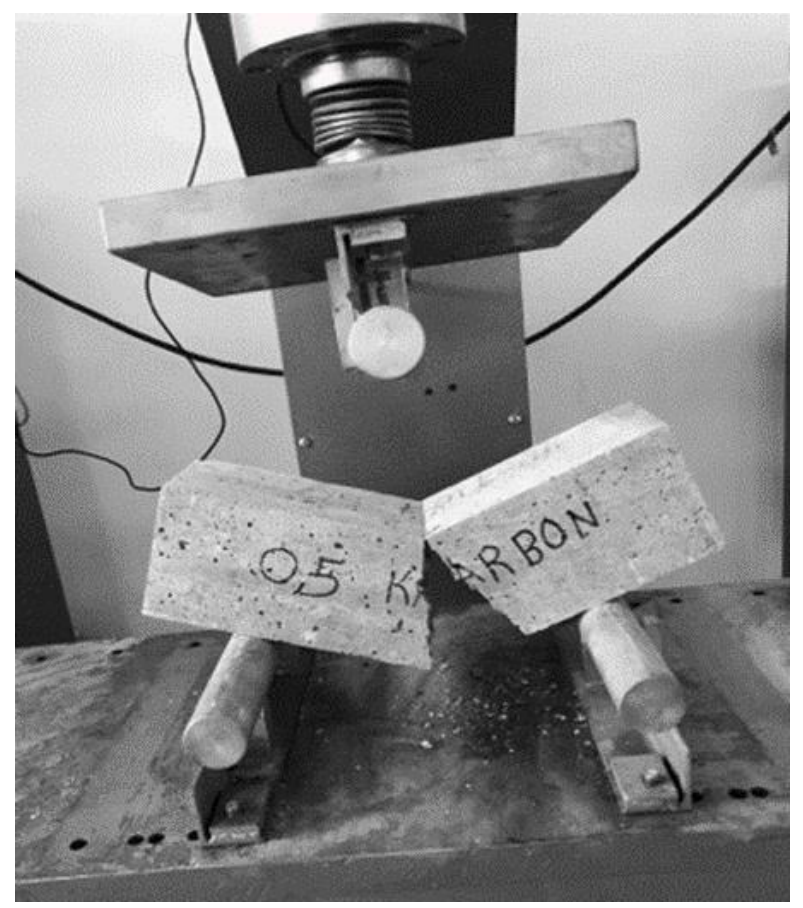

Şekil 1. Eğilme deneyi

Yeniden $20 \mathrm{~g}$ zımpara tozu sürtünme şeridi üzerine serpilir ve numune düşey eksen etrafinda $90^{\circ}$ çevrilir. Her numune için 22 devirden meydana gelen deney, numuneye 16 defa uygulanır. Deney numunesi iyice temizlendikten sonra numune hassas terazide tartılır ve ağırlık kayb1 not edilir.

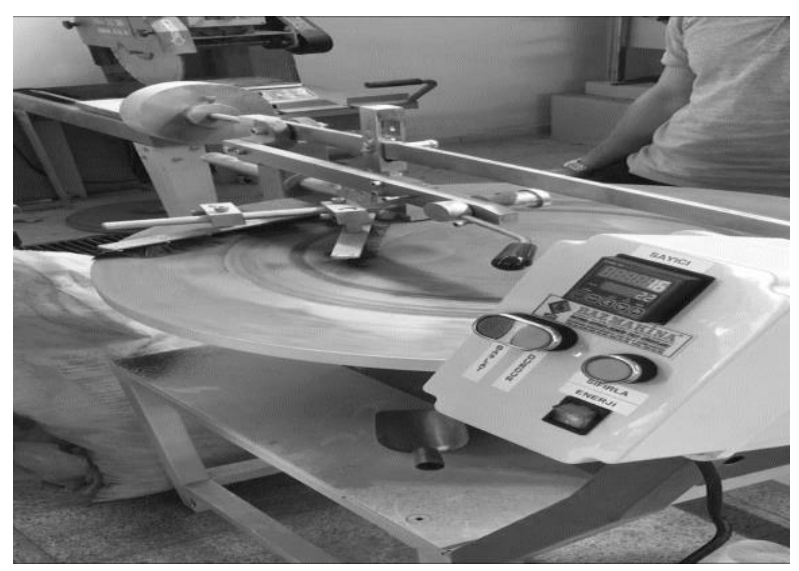

Şekil 2. Böhme deneyi mekanizması

\subsubsection{Arşimet Deneyi}

Tüm seriler üzerinde arşimet prensibi ile çalışan terazi yardımıyla porozite ve su emme özelikleri TS EN 1170-6 (1999) standardına uygun olarak belirlenmiştir. Beton numuneleri 28 gün sonunda kür havuzundan çıkartılıp tartının su içerisindeki sepete koyularak Arşimet Terazisi yardımıyla ağırlıkları kaydedilmiştir. Daha sonra yüzeyleri bir bez yardımı ile kurulanarak havadaki ağırlıkları alınmıştır. Numuneler $110^{\circ} \mathrm{C}$ 'de etüvde 24 saat boyunca kurutulup etüv kurusu haline getirilmiştir. Etüvden çıkan numuneler oda sicaklığına gelinceye kadar soğutulduktan sonra etüv kurusu ağırlıkları tartılmıştır. Ağırlık ölçümleri her seri için 3'er numune üzerinde yapılarak ortalama değerleri alınmıştır.

\subsubsection{Ultrases Deneyi}

Numunelerin ultrases geçiş hızı ölçümleri Şekil 3'deki Ultrases test cihazı (P-dalgası) ile yapılmıştır. 28 gün standart kür havuzunda bekletilen numuneler etüv kurusu hale getirilerek ultrases deneyi TS EN 12504-4 (2004) standardına göre uygulanmıştır. Numunelerin iki yüzeyi arasındaki mesafe kumpas yardımıyla ölçülüp, ölçüm yapılacak yüzeylerde hava boşluğunun kalmaması için ultrason jeli ile pürüzsüz olması sağlanmıştır. Propların (vericialıcı) arasına numune yerleştirilerek aynı hizaya getirilmiş ve cihaz çalıştırılmıştır. Cihazdaki ses dalgasının geçiş süresi kaydedilmiştir. Proplar arası ara mesafe ve kayıt aldığımız ses geçiş hızı yardımı ile formülde gerekli hesaplamalar yapılarak ultrases geçiş hızları hesaplanmıştır.

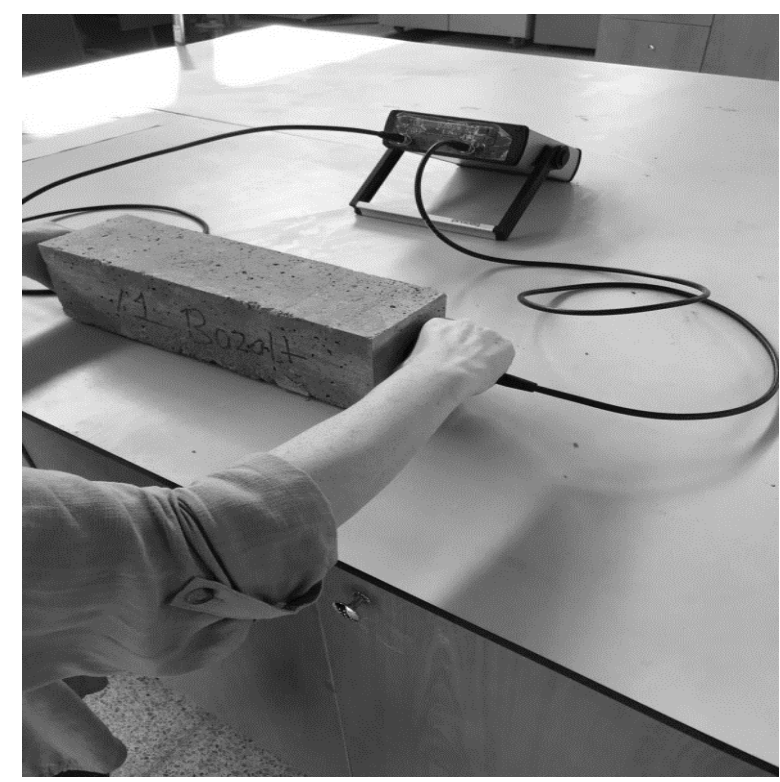

Şekil 3. Ultrases Deneyi

\section{Bulgular ve Tartışma}

\subsection{Fiziksel Özellikler}

Bazalt ve karbon takviyeli beton numunelerinin su emme yüzdeleri Şekil 4'te verilmiştir. Bazalt lif $\% 0.5$ oranında ilave edildiğinde referans numuneye göre su emme yüzdesinde $\% 9.38$ oranında düşüş olduğu ancak lif oranının \%1, $\% 1.5$ ve $\% 2$ oranında kullanıldığında sırasıyla 
$\% 6.45, \% 12.31$ ve $\% 16.42$ oranlarında artış yaşandığ 1 gözlenmiştir. Karbon lif $\% 0.5$ oranında ilave edildiğinde referans numuneye göre su emme yüzdesinde $\% 3,51$ oranında düşüş olduğu ancak lif oranının $\% 1, \% 1.5$ ve $\% 2$ oranında kullanıldığında sirasıla $\% 0.29, \quad \% 10.55$ ve \%17.59 oranlarında artış yaşandığı gözlenmiştir.
En fazla su emme yüzde değeri $\% 4.01$ oranında $\% 2 \mathrm{~K}$ numunesinde meydana gelmiştir. Lif oranının artışı ile birlikte daha boşluklu yapı meydana geldiğinden su emme değerleri de aynı doğrultuda artış göstermektedir. Bazaltın karbona oranla daha düşük su emme değerleri verdiği görülmektedir.

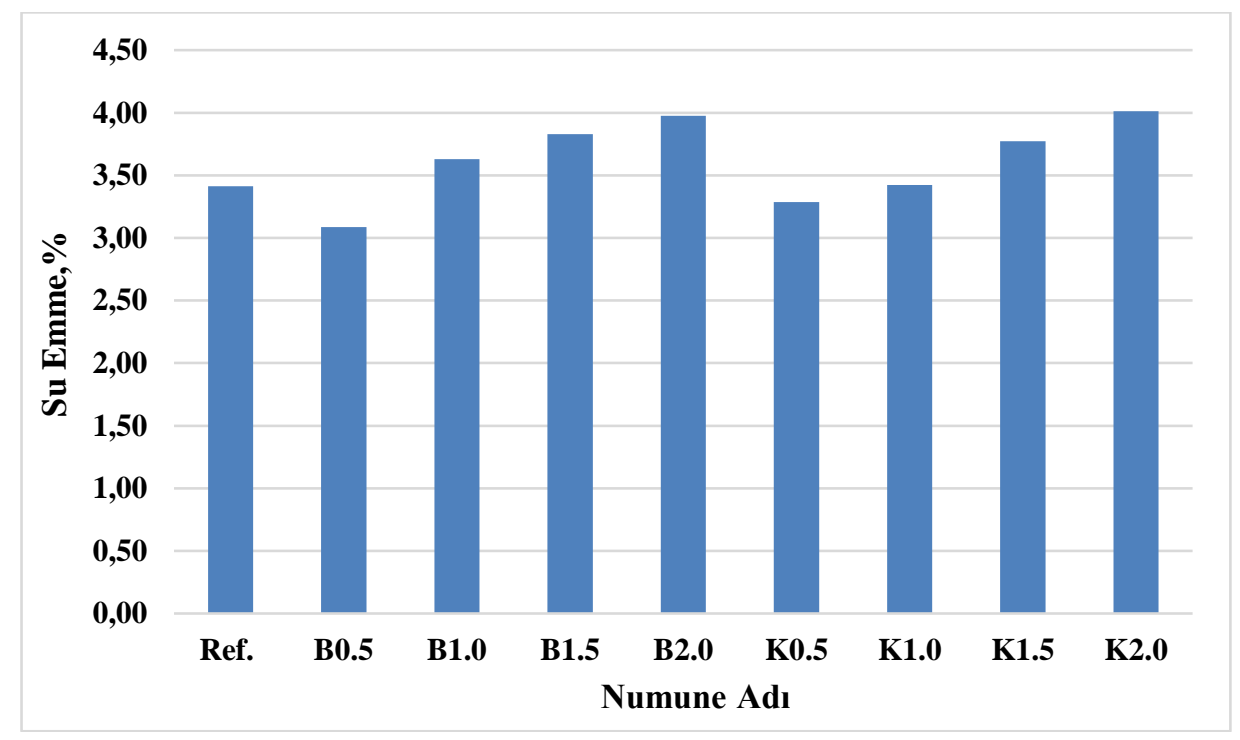

Şekil 4. Numunelerin su emme yüzde değerleri

Bazalt ve karbon takviyeli üretilen beton numunelerinin porozite yüzdeleri Şekil 5'te verilmiştir. Bazalt lif $\% 0.5$ oranında ilave edildiğinde referans numuneye göre su emme yüzdesinde $\% 9.83$ oranında düşüş olduğu ancak lif oranının $\% 1, \% 1.5$ ve $\% 2$ oranında kullanıldığında sirasiyla $\% 4.35, \quad \% 13.07$ ve \%15.69 oranlarında artış yaşandığı gözlenmiştir. Karbon lif $\% 0.5$ ve $\% 1$ oranında ilave edildiğinde referans numuneye göre su emme yüzdesinde sırasıyla $\% 3,11$ oranında düşüş olduğu ancak lif oranının $\% 1.5$ ve $\% 2$ oranında kullanıldığında sırasıyla \%11.33 ve \%16.56 oranlarında artış yaşandığı gözlenmiştir. En fazla porozite değeri $\% 9.36$ oranında $\% 2 \mathrm{~K}$ numunesinde meydana gelmiştir. Lif miktarının artmasıyla birlikte işlenebilirlikte meydana gelen güçlükler sonucun yerleşme problemi ortaya çıkmakta bundan kaynaklı boşluklu yapılar elde edildiğinden en fazla su emme değeri lif oranının en yüksek olduğu serilerde gözlemlenmiştir. Bazaltın karbona oranla daha düşük porozite değerleri verdiği görülmektedir.

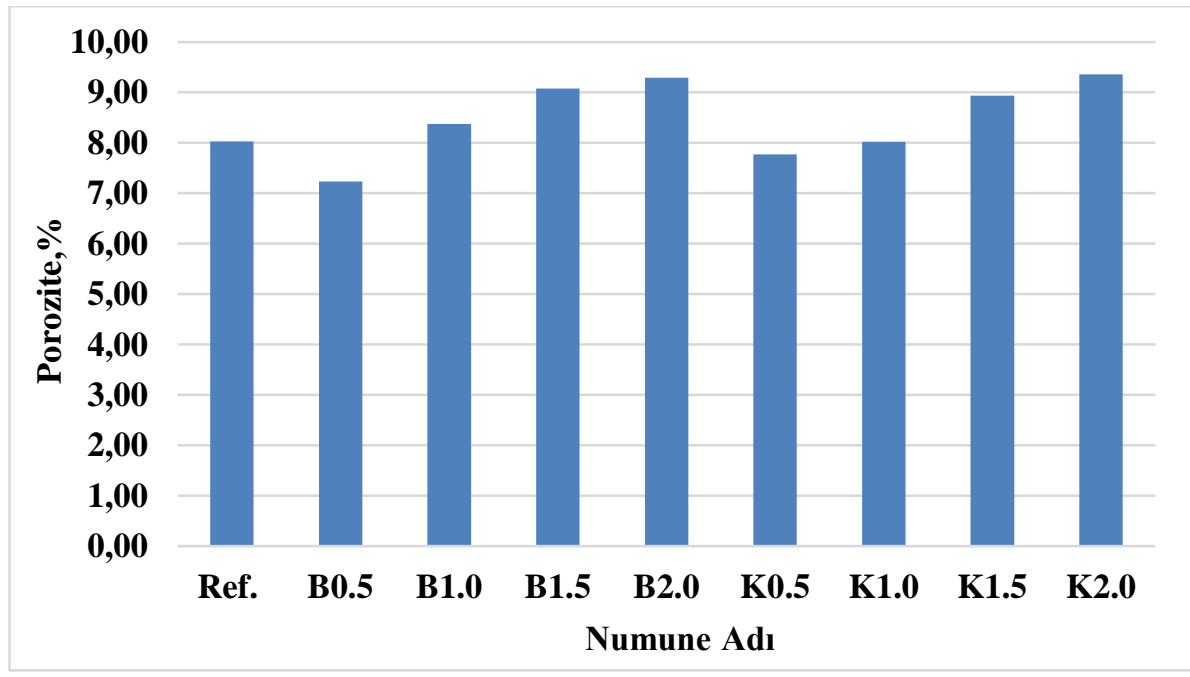

Şekil 5. Numunelerin porozite yüzde değerleri 
Bazalt ve karbon takviyeli üretilen beton numunelerinin ultrases geçiş hızları Şekil 6'da verilmiştir. Referans numuneye oranla lif ilavesi ile genel olarak ultrases geçiş hızlarının attığ görülmüsstür. Ultrases geçiş hızı beton içerisindeki boşlukların bir göstergesi olarak kabul edilir (Yaşar vd., 2004). Lif kullanımı ile betondaki boşluk oranının azalması ile birlikte daha yüksek ultrases geçiş hızları elde edilmiştir. En yüksek geçiş hızı \%2 oranında bazalt lifi ilave edilen beton numunelerinde $5155 \mathrm{~m} / \mathrm{sn}$ olarak ölçülmüştür. En düşük ultrses geçiş hızı \%1.5 oranında karbon lifi ilave edilen betonlarda 4902 $\mathrm{m} / \mathrm{sn}$ olarak ölçülmüştür. Bazalt lif kullanımında, karbon lif kullanımına göre daha yüksek ultrases geçiş hızları elde edilmiştir. Lif oranının artması ile bazalt lifinde karbon lifine oranla dana belirgin bir artış gözlemlenmiştir.

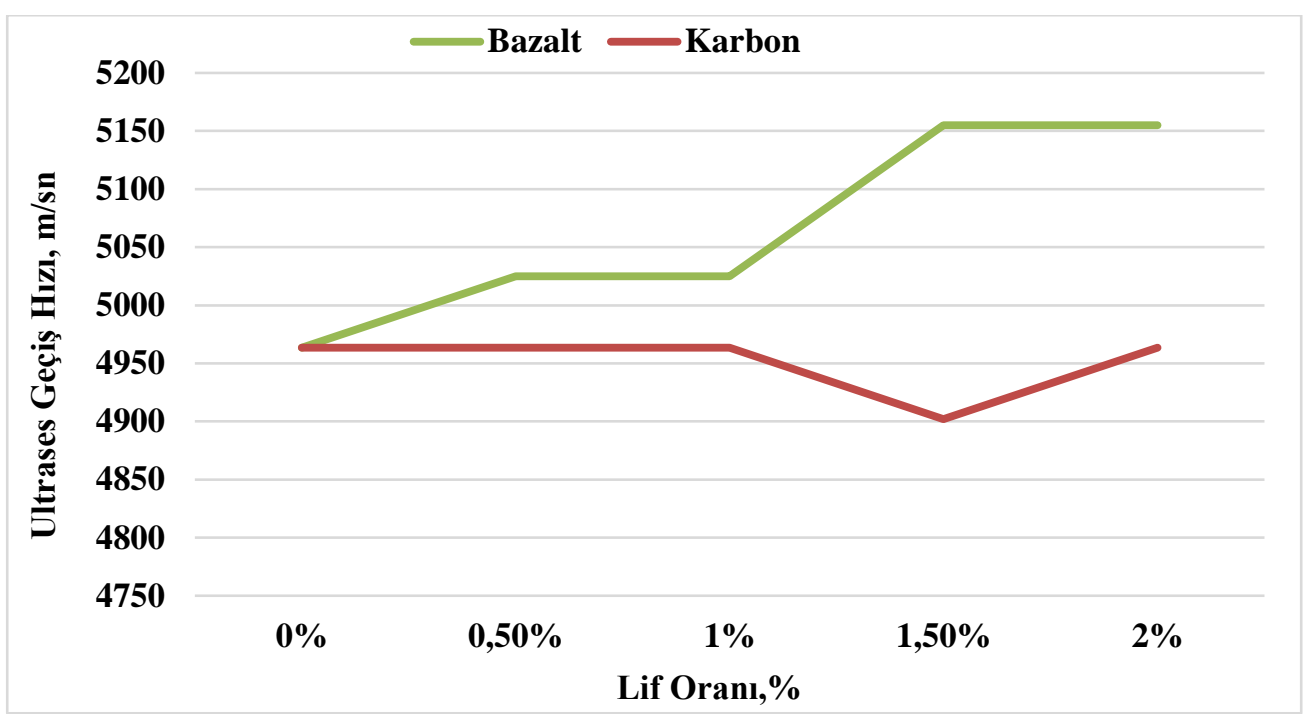

Şekil 6. Numunelerin ultrases geçiş hızı değerleri

Üretilen beton numunelerinin 28 gün sonunda hesaplanan ağırlık kayıpları Şekil 7'de verilmiştir. Lif kullanımı sonucunda ağırlık kayıplarında azalma meydana gelmiştir. Lif kullanımının betonların aşınmaya karşı direncini arttırdığ bilinmektedir (Kabay, 2014). Bazalt lif \%0.5, \%1, $\% 1.5$ ve $\% 2$ oranlarında kullanıldığında ağırlık kayıpları sirasiyla $\% 48.81, \% 46.45, \% 32.02$ ve $\%$ 13.12 oranlarında azalma meydana gelmiştir.
Karbon lif $\% 0.5$ ve $\% 1$ oranlarında kullanıldığında ağırlık kayıplarında sırasıyla $\% 33.59$ ve $\% 28.08$ oranlarında azalma olduğu, $\% 1.5$ ve $\% 2$ oranlarında kullanıldığında ağırlık kayıpları sirasiyla $\% 0,52$ ve $\% 11.02$ oranlarında artış görülmektedir. Bazalt lifinin kullanılması karbon lifinin kullanımına kıyasla aşınmaya karşı dirençli olduğu görülmüştür.

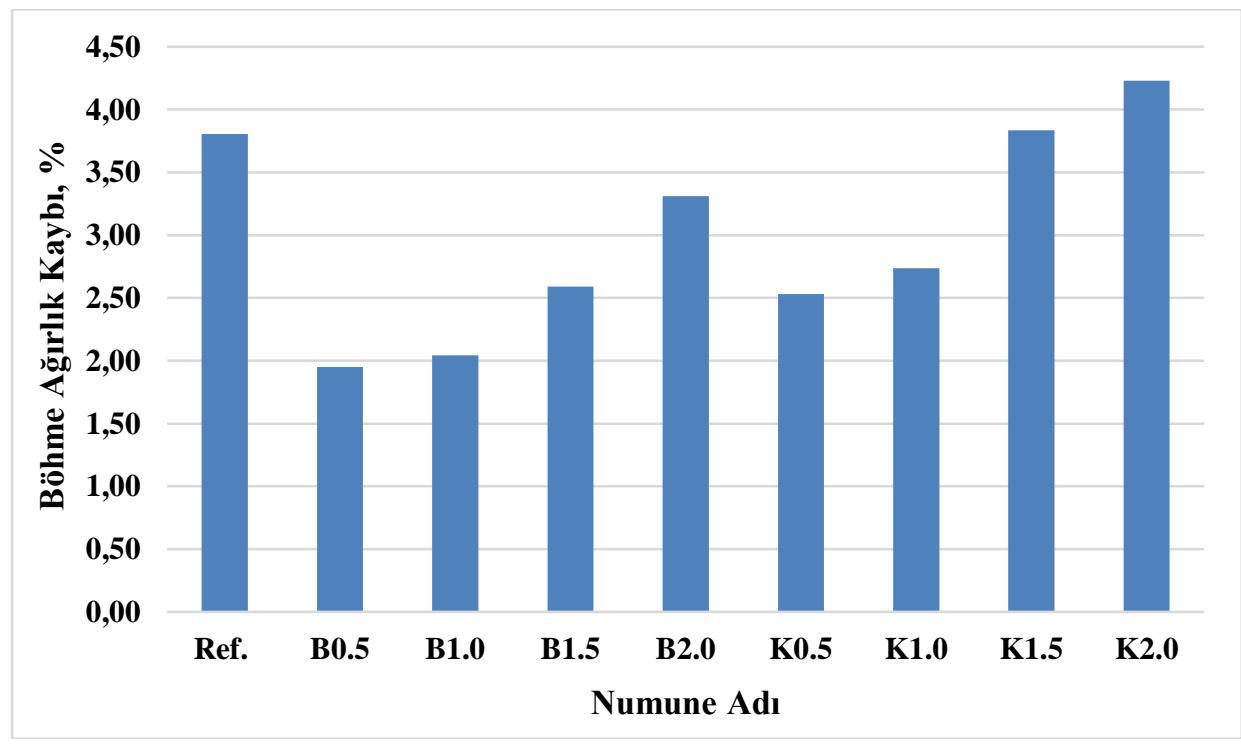

Şekil 7. Böhme ağırlık kaybı değerleri 


\subsection{Mekanik Özellikler}

Üretilen beton numunelerinin 7 ve 28 günlük basınç dayanımlanı sırasıyla Şekil 8 ve Şekil 9'da verilmiştir. Numunelerin 7 ve 28 günlük basınç dayanımları incelendiğinde bazalt lif takviyeli numuneler karbon lif takviyeli numunelere göre daha fazla dayanım sağladığı görülmektedir. Lif ilave oranları arttığında dayanım artışı meydana gelmiştir. En fazla 7 günlük basınç dayanımı $\% 0.5$ oranında bazalt lif takviyeli numunede $45.42 \mathrm{MPa}$ değerinde meydana gelmiştir. Bazalt lifi kullanımında \%0.5 oranında basınç dayanımında artıştan sonra azalış meydana gelirken, karbon lif oranında bu artış \%1.5 oranında kullanılması ile elde edilmiştir. Lifli kompozitler betonların basınç dayanımını arttırdığı ancak eğilme kadar önemli bir dayanım artışına sebep olmadığı bilinmektedir (Açıkgenç vd., 2015). Fiore ve ark. Yapımış olduğu çalışmada bazalt lifinin oranının artması ile birlikte basınç dayanımının azaldığını gözlemlemişlerdir (Fiore vd., 2015). Deneylerden elde edilen basınç dayanımındaki meydana gelen düşük oranda artış literatür ile benzerlik göstermektedir.

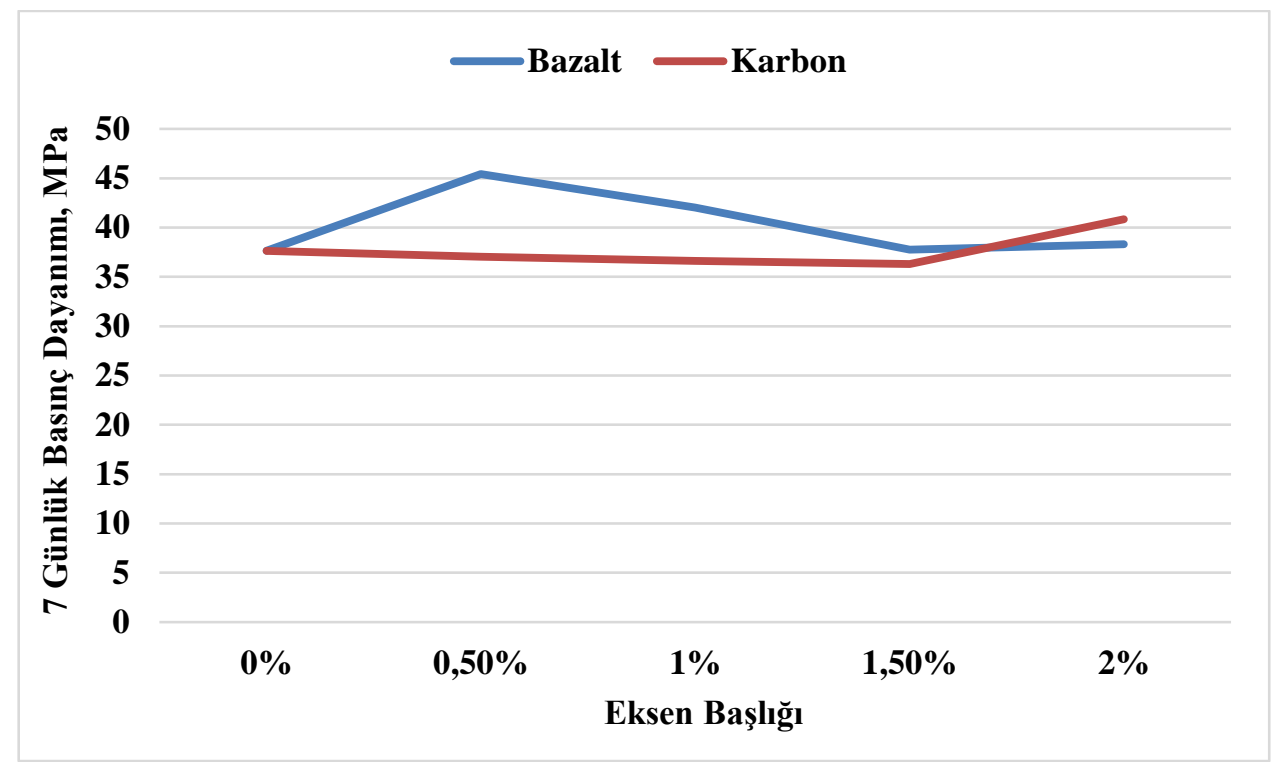

Şekil 8. Beton numunelerin 7 günlük basınç dayanım değerleri

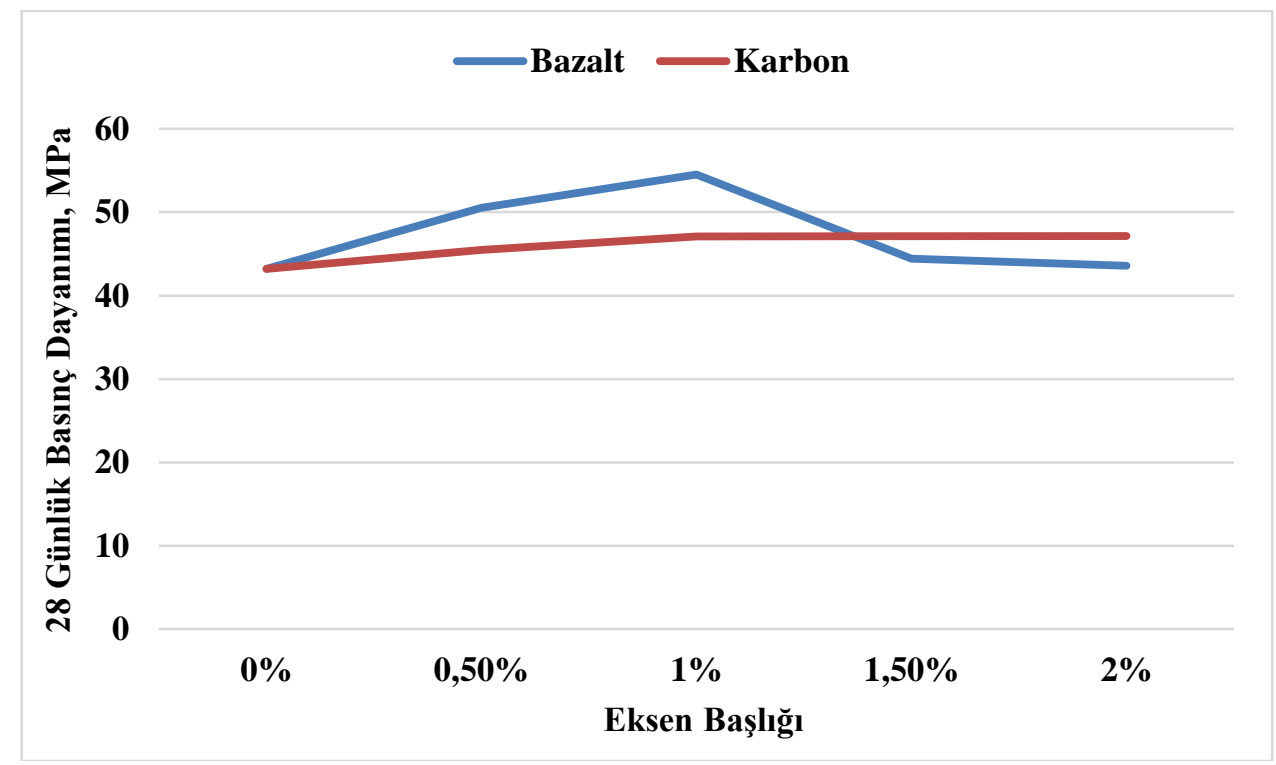

Şekil 9. Beton numunelerin 28 günlük basınç dayanım değerleri

Üretilen beton numunelerinin 28 günlük eğilme dayanımları Şekil 10'da verilmiştir. Lif takviyesi özellikle betonun eğilme dayanımını arttırmak için kullanılmaktadır ve eğilme dayanımları incelendiğinde lif kullanımı ile eğilme dayanımlarında artış gözlemlenmiştir. 
Numunelerin eğilme dayanımları incelendiğinde bazalt lif takviyeli numuneler karbon lif takviyeli numunelere göre daha fazla dayanım sağladığı görülmektedir. Lif ilave oranları arttığında dayanım artı̧̧ı meydana gelmiştir. En yüksek eğilme dayanımı \%1.5 oranında bazalt lifi takviyeli beton numunesinde $73.125 \mathrm{MPa}$ olarak, en düşük eğilme dayanımı ise lif içermeyen referans numunede meydana gelmiştir. Eğilme dayanımlarda artış lif takviyesi ile betonların maksimum eğilme dayanımıdır. Beton maksimum eğilme dayanımına ulaşınca çatlar, lifler devreye girer. Meydana gelen bu maksimum dayanım lifli kompozitin dayanımıdır (Mehta vd., 2006).

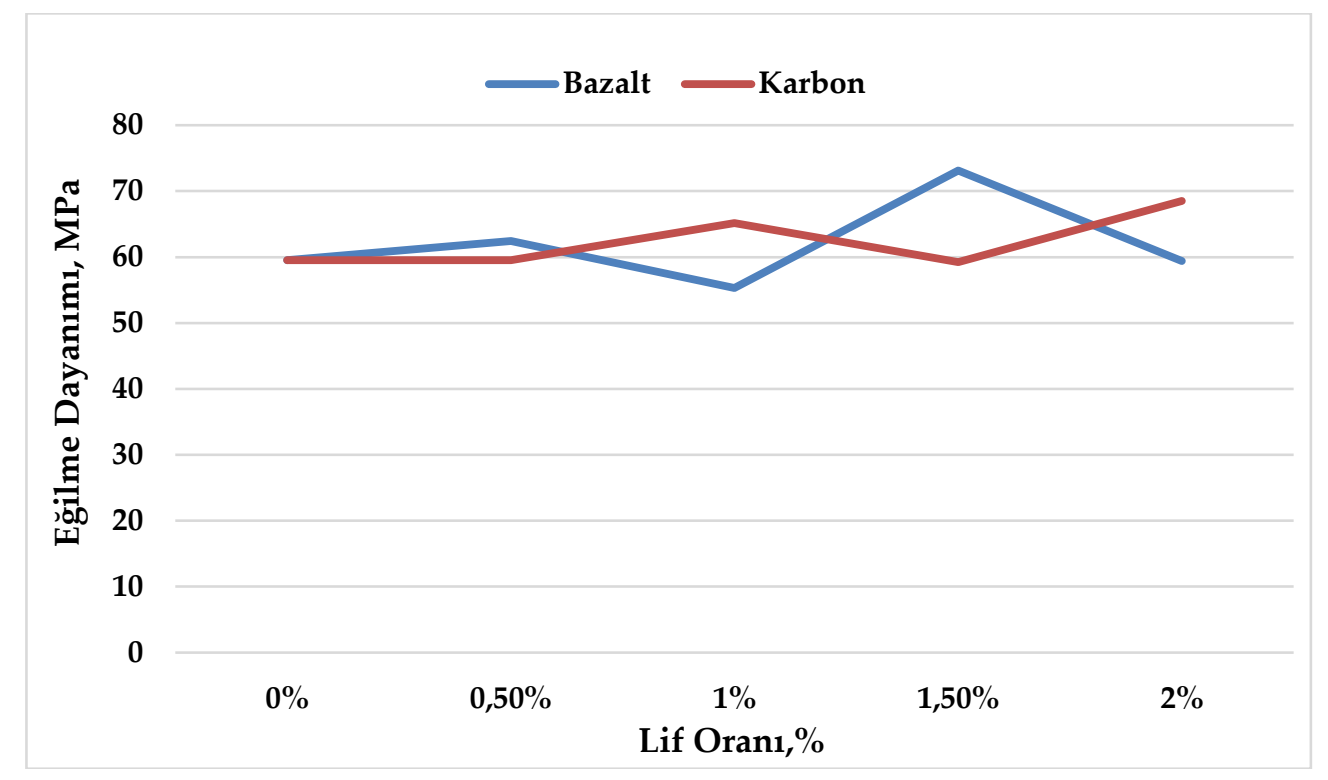

Şekil 10. Beton numunelerin 28 günlük eğilme dayanım değerleri

\section{Sonuçlar}

Bazalt ve karbon olmak üzere iki çeşit lif ilave edilen beton numunelerinin fiziksel ve mekanik özellikleri incelendiğinde uygulanan deneysel çalışmalarda aşağıdaki sonuçlar elde edilmiştir.

- Bazalt lif \%0.5 oranında ilave edildiğinde su emme yüzdesinde $\% 9.38$ oranında düşüş olduğu ancak lif oranının $\% 1, \% 1.5$ ve $\% 2$ oranında kullanıldığında sirasıyla $\% 6.45, \% 12.31$ ve $\% 16.42$ oranlarında artış yaşandığı gözlenmiştir.

- Karbon lif \%0.5 oranında ilave edildiğinde su emme yüzdesinde $\% 3,51$ oranında düşüş olduğu ancak lif oranının $\% 1, \% 1.5$ ve $\% 2$ oranında kullanıldığında sirasıyla $\% 0.29, \quad \% 10.55$ ve $\% 17.59$ oranlarında artış yaşandığı gözlenmiştir.

- Bazalt lif \%0.5 oranında ilave edildiğinde su emme yüzdesinde $\% 9.83$ oranında düşüş olduğu ancak lif oranının $\% 1, \% 1.5$ ve $\% 2$ oranında kullanıldığında sirasıly $\% 4.35, \% 13.07$ ve \%15.69 oranlarında artış yaşandığı gözlenmiştir.

- Karbon lif \%0.5 ve \%1 oranında ilave edildiğinde su emme yüzdesinde sirasıyla \%3,11 oranında düşüş olduğu ancak lif oranının $\% 1.5$ ve $\% 2$ oranında kullanıldığında sirasıyla \%11.33 ve \%16.56 oranlarında artış yaşandığı gözlenmiştir.

- Referans numuneye oranla lif ilavesi ile genel olarak ultrases geçiş hızlarının attığı görülmüştür. Lif kullanımı ile betondaki boşluk oranının azalması ile birlikte daha yüksek ultrases geçiş hızları elde edilmiştir.

- Bazalt lif kullanımında, karbon lif kullanımına göre daha yüksek ultrases geçiş hızları elde edilmiştir.

- Lif kullanımı sonucunda ağırlık kayıplarında azalma meydana gelmiştir.

- Bazalt lifinin kullanılması karbon lifinin kullanımına kıyasla aşınmaya karşı dirençli olduğu görülmüştür.

- Numunelerin 7 ve 28 günlük basınç dayanımları incelendiğinde bazalt lif takviyeli numuneler karbon lif takviyeli numunelere göre daha fazla dayanım sağladığı görülmektedir. Lif ilave oranları arttığında dayanım artışı meydana gelmiştir.

- Lif takviyesi özellikle betonun eğilme dayanımını arttırmak için kullanılmaktadır ve eğilme dayanımları incelendiğinde lif kullanımı ile eğilme dayanımlarında artış gözlemlenmiştir.

- Numunelerin eğilme dayanımları incelendiğinde bazalt lif takviyeli numuneler karbon lif takviyeli numunelere göre daha fazla dayanım sağladığ görülmektedir.

- Sonuç olarak lif takviyeli betonlarda kullanılan bazalt lifinin karbon lifine göre daha iyi sonuçlar verdiği, ancak lif kullanımının hedeflendiği gibi özellikle eğilme ve aşınma dayanımlarını arttırıcı etkisi görülmüştür. 


\section{Kaynaklar}

Açıkgenç, M., 2015. A Graphic Based Approach for the Mix Design of Steel Fiber Reinforced Concrete, Ph.D. Thesis, Firat University, Elazig, Turkey, p. 186 (in Turkish).

Afroughsabet, V., Biolzi, L. ve Ozbakkaloglu, T., 2016. High-performance Fiber-reinforced Concrete: A Review, Journal of Materials Science, 51(14) 6517-6551.

Alberti, M.G., Enfedaque, A. ve Gálvez, J.C., 2017. Fibre Reinforced Concrete with A Combination of Polyolefin and Steel-hooked Fibres, Composite Structures, 171, 317-325.

Barr, B., Hoseinian, S.B. ve Beygi, M.A., 2003. Shrinkage of Concrete Stored in Natural Environments. Cement and Concrete Composites, 25, 19-29.

Biolzi, L., Cattaneo, S. ve Guerrini, G.L. 2000. Fracture of Plain and Fiber-reinforced High Strength Mortar Slabs with EA and ESPI Monitoring. Applied Composite Materials, 7, 112.

Biolzi, L. ve Cattaneo, S., 2017. Response of Steel Fiber Reinforced High Strength Concrete Beams: Experiments and Code Predictions. Cement and Concrete Composites, 77, 1-13.

Branston, J., Das, S., Kenno, S.Y. ve Taylor, C., 2016. Mechanical Behaviour of Basalt Fibre Reinforced Concrete, Construction and Building Materials, 124, 878-886.

Campione, G., Mendola, L.L. ve Papia M., 2006. Shear Strength of Fiber Reinforced Beams with Stirrups. Structural Engineering and mechanics, 24(1), 107-36.

Chung, D.D.L., 2000. Cement Reinforced with Short Carbon Fibers: A Multifunctional Material. Composites Part B: Engineering, 31(6), 511526.

Craig, R., 1987. Flexural Behaviour ve Design of Reinforced Fiber Concrete Members, SP-105. American Concrete Institute, Detroit, 517-563.

Fiore V, Scalici T, Di Bella G ve Valenza A., 2015. A Review on Basalt Fibre and Its Composites. Composites Part B: Engineering, 74, 74-94.

Gao, J., Sha, A., Wang, Z., Hu, L., Yun, D., Liu, Z. ve Huang, Y., 2018. Characterization of Carbon Fiber Distribution in Cement-based Composites by Computed Tomography. Construction and Building Materials, 177, 134-147.

Habel, K., Viviani, V., Denarié, E. ve Brühwiler, E., 2006. Development of the Mechanical
Properties of an Ultra-high Performance Fiber Reinforced Concrete (UHPFRC), Cement and Concrete Research, 36(7) 1362-1370.

Hameed, R., Turatsinze, A., Duprat, F. ve Sellier, A., 2010. A Study on the Reinforced Fibrous Concrete Elements Subjected to Uniaxial Tensile Loading. KSCE Journal Civil Engineering, 14, 547-556.

Jiang, C., Fan, K., Wu, F. ve Chen, D., 2014. Experimental Study on the Mechanical Properties and Microstructure of Chopped Basalt Fibre Reinforced Concrete, Materials \& Design, 58, 187-193.

Kabay N. 2014. Abrasion Resistance ve Fracture Energy of Concretes with Basalt Fibre. Construction and Building Materials, 50, 95101.

Kaufmann, W. 1998. Strength and Deformations of Structural Concrete Subjected to InPlane Shear and Normal Forces. Report No. 234, Institute of Structural Engineering, ETH, Zurich.

Kizilkanat, A.B., Kabay, N., Akyüncü, V., Chowdhury, S. ve Akça, A.H., 2015. Mechanical Properties and Fracture Behavior of Basalt and Glass Fiber Reinforced Concrete: An Experimental Study, Construction and Building Materials, 100, 218224.

Li, Z., Lara, M.A.P. ve Bolander, J.E., 2006. Restraining Effects of Fibers During Nonuniform Drying of Cement Composites. Cement and Concrete Research, 36, 1643-1652.

Mehta, P.K. ve Monteiro, P.J.M., 2006. Concrete: Microstructure, Properties, and Materials. 3rd Edition. McGraw-Hill, New York.

Park, J.J., Yoo, D.Y., Park, G.J. ve Kim, S.W., 2017. Feasibility of Reducing the Fiber Content in Ultra-high-Performance Fiber-reinforced Concrete under Flexure. Materials, 10, 118.

Ralegaonkar, R., Gavali, H., Aswath, P. ve Abolmaali, S., 2018. Application of Chopped Basalt Fibers in Reinforced Mortar: A review, Construction and Building Materials, 164, 589-602.

Sivakumar, A. ve Santhanam, M., 2007. Mechanical Properties of High Strength Concrete Reinforced with Metallic and Non-metallic Fibres. Cement and Concrete Composites, 29, 603-608.

Shah, S.P., 1992. Do Fibers Increase the Tensile Strength of Cement-based Matrix? ACI Materials Journal, 88, 595-602.

Thomas, J.A., 2007. Ramaswamy, Mechanical Properties of Steel Fiber-reinforced Concrete, 
Journal of Materials in Civil Engineering, 19(5), 385-392.

TS EN 197-1, 2012. Cement- Stage 1: General Cements - Component, TSE, Ankara Turkey.

TS 706 EN 12620+A1 2009. Beton Agregalar1, TSE, Ankara, Türkiye.

TS EN 12390-4, 2019. Beton-Sertleşmiş Beton Deneyleri-Bölüm 3: Deney Numunelerinin Basınç Dayanımının Tayini, TSE, Ankara, Türkiye.

TS EN 12390-4, 2019. Beton-Sertleşmiş Beton Deneyleri-Bölüm 4: Basınç Dayanım Deney Makinelerinin Özellikleri, TSE, Ankara, Türkiye

TS EN 12390-5 2019. Beton-Sertleşmiş Beton Deneyleri-Bölüm 5: Deney Numunelerinin Eğilme Dayanımının Tayini, TSE, Ankara Türkiye

TS 2824 EN 1338, 2005, Zemin Döşemesi İçin Beton Kaplama Blokları-Gerekli Şartlar ve Deney Metotları, Türk Standartları Enstitüsü, Ankara, Türkiye.

TS EN 1170-6, 1999. Ön Yapımlı Beton MamullerCam Elyaf Takviyeli Çimento (ctc) Deney Metodu-Bölüm 6: Suya Daldırma Yoluyla Su Emme ve Kuru Yoğunluk Tayini, TSE, Ankara, Türkiye.

TS EN 12504-4 2004. Beton Deneyleri-Bölüm 4: Ultrases Geçiş Hızının Tayini, TSE, Ankara Türkiye.

Yaşar, E., Erdogan, Y. ve Kılıç, A., 2004. Effect of Limestone Aggregate Type and Water-Cement Ratio on Concrete Strength. Materials Letters, 58 (5), 772-777.

URL-1, https://www.dostkimya.com/tr. 05 Mart 2020. 